\title{
Effect of Temperature and Electric Field on the Damping and Stiffness Characteristics of ER Fluid Short Squeeze Film Dampers
}

\author{
H. P. Jagadish ${ }^{1}$ and L. Ravikumar ${ }^{2}$ \\ ${ }^{1}$ Department of Mechanical Engineering, BMS Evening College of Engineering, Bangalore 560 019, India \\ ${ }^{2}$ Department of Mechanical Engineering, BMS College of Engineering, Bangalore 560 019, India \\ Correspondence should be addressed to H. P. Jagadish; jagadishhawaldar@yahoo.com
}

Received 5 June 2013; Accepted 17 September 2013

Academic Editor: Marimuthu Uthayakumar

Copyright (C) 2013 H. P. Jagadish and L. Ravikumar. This is an open access article distributed under the Creative Commons Attribution License, which permits unrestricted use, distribution, and reproduction in any medium, provided the original work is properly cited.

\begin{abstract}
Squeeze film dampers are novel rotor dynamic devices used to alleviate small amplitude, large force vibrations and are used in conjunction with antifriction bearings in aircraft jet engine bearings to provide external damping as these possess very little inherent damping. Electrorheological (ER) fluids are controllable fluids in which the rheological properties of the fluid, particularly viscosity, can be controlled in accordance with the requirements of the rotor dynamic system by controlling the intensity of the applied electric field and this property can be utilized in squeeze film dampers, to provide variable stiffness and damping at a particular excitation frequency. The paper investigates the effect of temperature and electric field on the apparent viscosity and dynamic (stiffness and damping characteristics) of ER fluid (suspension of diatomite in transformer oil) using the available literature. These characteristics increase with the field as the viscosity increases with the field. However, these characteristics decrease with increase in temperature and shear strain rate as the viscosity of the fluid decreases with temperature and shear strain rate. The temperature is an important parameter as the aircraft jet engine rotors are located in a zone of high temperature gradients and the damper fluid is susceptible to large variations in temperature.
\end{abstract}

\section{Introduction}

The application of controllable fluids in engineering is an area which began to be explored in the early 1980s and fluids of interest in this study are materials that respond to an applied electric field with a remarkable change in its rheological behavior. The essential characteristic of these controllable fluids is their capability to change from a liquid state into a solid-like gel under the action of an electric field. These materials are commonly called electrorheological (ER) fluids and are normally low-viscosity colloidal suspensions. When an electric field is applied, the fluid undergoes a seemingly reversible transition to a solid in milliseconds, being able to support considerable stress under static load without yield. Willis M. Winslow (1949) was the first to discover an ER fluid and introduced the concept of controlling the apparent viscosity of an electroviscous fluid by using an electric field.
ER fluids usually consist of a base fluid, usually some type of low viscosity insulating liquid, mixed with non-conductive particles (in the range of $1-10 \mu \mathrm{m}$ diameter), such as cornstarch, gypsum and lithium salt.

Since its mechanical properties can be easily controlled within a wide range by applied voltage (almost from a pure liquid to a solid), the ER fluid could be used as an electrical and mechanical interface in various industrial areas. ER fluids can be utilized in automobile clutch, brake, and damping systems. In a vibratory damping system, the fluid is to be of variable viscosity which is best satisfied by the application of smart fluids (ER and MR fluid). The change in the field induced shear stress produces a change in their apparent viscosity and this property is successfully utilized in applications involving valves, dampers, clutches, and adaptive structures but applications in rotor dynamics are far from satisfactory and require considerable attention [1-3]. Limited 
information is available regarding the stiffness and damping characteristics of ER fluid and their applications in active journal bearings and squeeze film dampers. While general aspects and applications of MR and ER fluids have been dealt with to some extent $[4,5]$, sharing their promising characteristics, it was only in the last decade that some pieces of literature have appeared on rotor dampers $[6,7]$. Since the available literature regarding the effect of temperature on the stiffness and damping characteristics of ER Fluid squeeze film dampers is very scanty, this paper investigates these aspects on a short squeeze film damper using the relation obtained between viscosity and temperature for a particular ER fluid which is a suspension of diatomite in transformer oil.

\section{The Herschel-Bulkley Model}

The one-dimensional Herschel-Bulkley model is used to model the shear thinning of ER fluid in the post-yield region. The constitutive equation for this model [9] is

$$
\begin{gathered}
\dot{\gamma}=0, \quad \tau \leq \tau_{\mathrm{yd}} \\
\tau=\tau_{\mathrm{yd}} \operatorname{sgn}(\dot{\gamma})+K \dot{\gamma}, \quad \tau \geq \tau_{\mathrm{yd}},
\end{gathered}
$$

where $\tau$ is the shear stress, $\dot{\gamma}$ is the shear strain rate, and $\tau_{\mathrm{yd}}$ is the dynamic yield stress. $K$ and $n_{1}$ are two parameters that describe the magnitude and slope of the curve. The parameter $K$ is sometimes referred to as the "consistency index." The exponent $n_{1}$ is dimensionless and is called the "behavior index." Both $K$ and $n_{1}$ depend on material properties and working conditions such as friction and temperature.

For steady shear flow $\left(|\tau|>\tau_{\text {yd }}\right)$, assume that $\dot{\gamma}>0$, (1b) can be written as

$$
\tau=\left(\tau_{\mathrm{yd}}+K \dot{\gamma}^{n_{1}-1}\right) \dot{\gamma}
$$

The apparent viscosity thus is

$$
\eta_{\mathrm{app}}=K \dot{\gamma}^{n_{1}-1}
$$

For shear thinning of ER suspensions with $0<n_{1}<1$, the apparent viscosity decreases with the increment of shear rate. The temperature affects both the values $K$ and $n_{1}$ and is responsible for the variation in the apparent viscosity of the ER fluid.

\section{Temperature Effect on Viscosity of ER Fluid}

Changes in the temperature of ER fluid due to working conditions like friction, or electrical power dissipation, may influence its performance in ER devices. The temperature decreases the viscosity of the ER fluid and consequently affects both the static and dynamic characteristics of the squeeze film damper. The viscosity-temperature relation of the ER Fluid at a particular electric field intensity can be modeled by the exponential decay type Reynolds equation or the Arrhenius equation outlined as (4) and (5), respectively, as

$$
\eta_{\text {app }}(T)=\eta_{0} \exp (-B T)
$$

where $T$ is the temperature and $\eta_{0}$ and $B$ are coefficients. This is an empirical model that usually works for a limited range of temperatures

$$
\eta_{\text {app }}(T)=\eta_{0} \exp \left(\frac{E}{R T}\right)
$$

where $E$ is the activation energy and $R$ is the universal gas constant. A first-order fluid is another name for a power law fluid with exponential dependence of viscosity on temperature.

This can be also be presented as

$$
\eta_{\text {app }}(T)=\eta_{0} \exp \left(\frac{B}{T}\right)
$$

where $B=E / R$.

\section{Stiffness and Damping Characteristics of Squeeze Film Dampers with Orbital Motion}

These squeeze film dampers (Figure 2) find application in the air craft engine rotors and are usually mounted on rolling element bearings, with little or no inherent damping to fight the unbalance response, especially at critical speeds, and to eliminate rotor dynamic instabilities. The coordinates of the orbit are presented as [10]

$$
\begin{gathered}
z=e \cos \omega t, \\
y=e \sin \omega t, \\
r=e, \\
r=V_{r}=0, \\
V_{t}=e \omega .
\end{gathered}
$$

Ignoring the stiffness terms, the radial and tangential forces acting on the system are

$$
\begin{aligned}
& F_{r}=C_{r r} V_{r}+C_{r t} V_{t}=C_{r t} \omega e, \\
& F_{t}=C_{t r} V_{r}+C_{t t} V_{t}=C_{t t} \omega e .
\end{aligned}
$$

The direct damping coefficient is

$$
C_{t t}=\frac{F_{t}}{\omega e},
$$

and the cross-coupled damping coefficient is

$$
C_{r t}=\frac{F_{r}}{\omega e} .
$$

The radial component of the force $F_{r}$ is considered as a stiffness force defined as the direct stiffness coefficient given by

$$
K_{r r}=\frac{F_{r}}{e}=C_{r t} \omega
$$

The squeeze film velocity is

$$
\frac{\partial h}{\partial t}=e \omega \sin \theta
$$




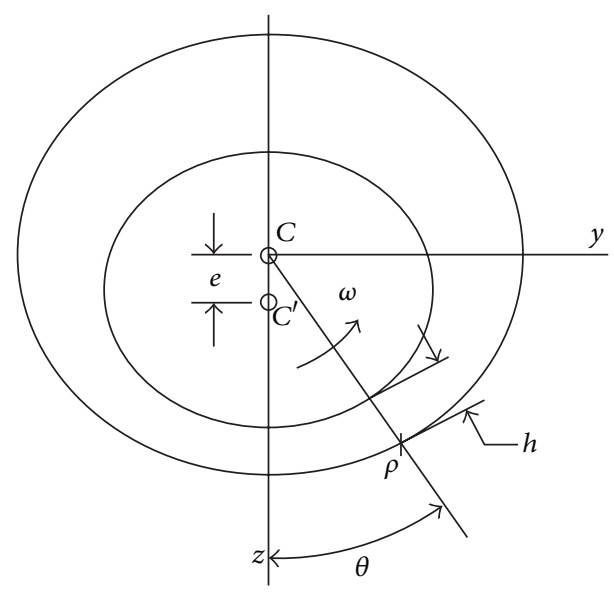

FIGURE 1: Squeeze film dampers with orbital motion.

The Reynolds equation for the present case with zero spin velocity for the short bearing case reduces to

$$
\frac{1}{r^{2}} \frac{\partial}{\partial \theta}\left[h^{3} \frac{\partial p}{\partial \theta}\right]+h^{3} \frac{\partial^{2} p}{\partial x^{2}}=12 \eta_{\mathrm{app}} \sin \theta
$$

The governing Reynolds equation for the short bearing case with zero spin velocity is

$$
\frac{1}{r^{2}} \frac{\partial}{\partial \theta}\left[h^{3} \frac{\partial p}{\partial \theta}\right]+h^{3} \frac{\partial^{2} p}{\partial x^{2}}=12 \eta_{\text {app }} e \omega \sin \theta .
$$

The short bearing approximation is applicable in cases in which the end seals are absent. For the short bearing approximation, the journal axis remains parallel to the bearing under the steady state operating condition. In such a case, the change in pressure in the circumferential direction is negligible in relation to the pressure change in axial direction, The Reynolds equation modifies to

$$
h^{3} \frac{d^{2} p}{d x^{2}}=12 \eta_{\text {app }} e \omega \sin \theta .
$$

The pressure distribution in the film is obtained by integration as

$$
p=\frac{6 \eta_{\mathrm{app}} \omega}{h^{3}} \frac{d h}{d \theta} \frac{x^{2}}{2}+\frac{A}{h^{3}} x+B .
$$

The constants in the above equation are evaluated from the boundary conditions

$$
p=0 \quad \text { at } x= \pm \frac{L}{2},
$$

where the coordinate system of Figure 1 is reckoned midway along the length $L$ of the bearing (perpendicular to the plane of the paper). The two constants are evaluated to give the pressure, $p$, as

$$
p=\frac{3 \eta_{\mathrm{app}} \omega}{h^{3}} \frac{d h}{d \theta}\left(x^{2}-\frac{L^{2}}{4}\right) .
$$

Using the film thickness Equation and ignoring the pressure distribution in the diverging wedge, that is, using the half Sommerfeld condition, one gets

$$
\begin{gathered}
p_{\theta}-p_{o} \\
=\frac{6 \eta_{\text {app }} \omega n\left(L^{2} / 4-x^{2}\right)}{c^{2}}\left[\frac{\sin \theta}{(1+n \cos \theta)^{3}}\right] \quad \text { for } 0 \leq \theta \leq \pi, \\
p_{\theta}-p_{\mathrm{o}}=0 \quad \text { for } \pi<\theta<2 \pi .
\end{gathered}
$$

Considering the equilibrium of the journal, the load capacity can be obtained from the integration of the following equations:

$$
\begin{aligned}
& 2 \int_{0}^{\pi} \int_{0}^{L / 2} \operatorname{prcos} \theta d x d \theta=-W \cos \alpha, \\
& 2 \int_{0}^{\pi} \int_{0}^{L / 2} \operatorname{prsin} \theta d x d \theta=-W \sin \alpha,
\end{aligned}
$$

where

$$
\begin{gathered}
W \sin \alpha=\frac{\pi \eta_{\mathrm{app}} \omega D n L^{3}}{8 c^{2}\left(1-n^{2}\right)^{3 / 2}}, \\
W \cos \alpha=\frac{\eta_{\mathrm{app}} \omega D n^{2} L^{3}}{2 c^{2}\left(1-n^{2}\right)^{2}} .
\end{gathered}
$$

The load capacity, $W$, is

$$
W=\frac{\eta_{\mathrm{app}} \omega r n L^{3}}{2 c^{2}\left(1-n^{2}\right)^{2}} \sqrt{16 n^{2}+\pi^{2}\left(1-n^{2}\right)} .
$$

The radial and the tangential force generated in the damper are components of the load capacity and are defined as

$$
\begin{gathered}
F_{r}=W \cos \alpha=\frac{\eta_{\mathrm{app}} \omega D n^{2} L^{3}}{c^{2}\left(1-n^{2}\right)^{2}}, \\
F_{t}=W \sin \alpha=\frac{\pi \eta_{\mathrm{app}} \omega D n L^{3}}{4 c^{2}\left(1-n^{2}\right)^{3 / 2}} .
\end{gathered}
$$

The direct stiffness, direct damping, and cross-coupled damping coefficients are, respectively,

$$
\begin{gathered}
K_{\mathrm{ds}}=\frac{\eta_{\mathrm{app}} \omega D n L^{3}}{c^{3}\left(1-n^{2}\right)^{2}}, \\
C_{\mathrm{ds}}=\frac{\pi \eta_{\mathrm{app}} D L^{3}}{4 c^{3}\left(1-n^{2}\right)^{3 / 2}}, \\
C_{r t s}=\frac{\eta_{\mathrm{app}} D n L^{3}}{c^{3}\left(1-n^{2}\right)^{2}} .
\end{gathered}
$$


TABle 1: Damper specifications.

\begin{tabular}{lcc}
\hline Description & \multicolumn{2}{c}{ Parameters } \\
\hline Clearance, $c, \mathrm{~mm}$ & 0.1 & 0.2 \\
Length, $L, \mathrm{~mm}$ & 30 & 40 \\
Diameter, $D, \mathrm{~mm}$ & 100 & 100 \\
$L / D$ ratio & 0.3 & 0.4 \\
Excitation frequency, $\omega \mathrm{rad} / \mathrm{sec}$ & 100 & 100 \\
Eccentricity ratio, $n$ & 0.1 & 0.1 \\
\hline
\end{tabular}

TABLE 2: (a) Values of the consistency index, $K$ [8]. (b) Values of the exponent, $n_{1}[8]$.

(a)

\begin{tabular}{lcccc}
\hline$T\left({ }^{\circ} \mathrm{C}\right)$ & 20 & 40 & 60 & 80 \\
$E=0 \mathrm{kV} / \mathrm{mm}$ & 0.045 & 0.038 & 0.028 & 0.0126 \\
$E=2.5 \mathrm{kV} / \mathrm{mm}$ & 8.91 & 5.57 & 2.46 & 0.4 \\
\hline
\end{tabular}

(b)

\begin{tabular}{lcccc}
\hline$T\left({ }^{\circ} \mathrm{C}\right)$ & 20 & 40 & 60 & 80 \\
$E=0 \mathrm{kV} / \mathrm{mm}$ & 0.86 & 0.861 & 0.873 & 0.957 \\
$E=2.5 \mathrm{kV} / \mathrm{mm}$ & 0.057 & 0.129 & 0.256 & 0.551 \\
\hline
\end{tabular}

TABLE 3: Constants $\eta_{0}$ and $B$.

\begin{tabular}{lcccc}
\hline $\begin{array}{l}\text { Governing } \\
\text { equation }\end{array}$ & \multicolumn{2}{c}{$E=0 \mathrm{kV} / \mathrm{mm}$} & \multicolumn{2}{c}{$E=2.5 \mathrm{kV} / \mathrm{mm}$} \\
& 2 & 4 & 2 & 4 \\
\hline $\begin{array}{l}\text { Reynolds } \\
\text { equation }\end{array}$ & & & & \\
$\eta_{0}$ & 0.05322 & 0.04383 & 12.899 & 3.489871 \\
$\quad B$ & 0.01324 & 0.00839 & 0.0512 & 0.018498 \\
$\begin{array}{l}\text { Arrhenius } \\
\text { equation }\end{array}$ & & & & \\
$\quad \eta_{0}$ & 0.02405 & 0.02650 & 0.5983 & 1.15023 \\
$B$ & 10.5892 & 6.70760 & 40.944 & 14.79864 \\
\hline
\end{tabular}

\section{Methodology Proposed}

The effect of electric field intensity and temperature on the theoretical squeeze film dynamic (damping and stiffness) characteristics can be obtained using the viscositytemperature relations [8] using the damper specifications and relevant ER fluid data outlined in Tables 1, 2(a), and 2(b), respectively.

\section{Results and Discussions}

The theoretical results are discussed under two headings:

(a) effect of temperature on the viscosity and dynamic characteristics (stiffness and damping characteristics),

(b) effect of electric field intensity and shear strain rate on the viscosity and dynamic characteristics (stiffness and damping characteristics).

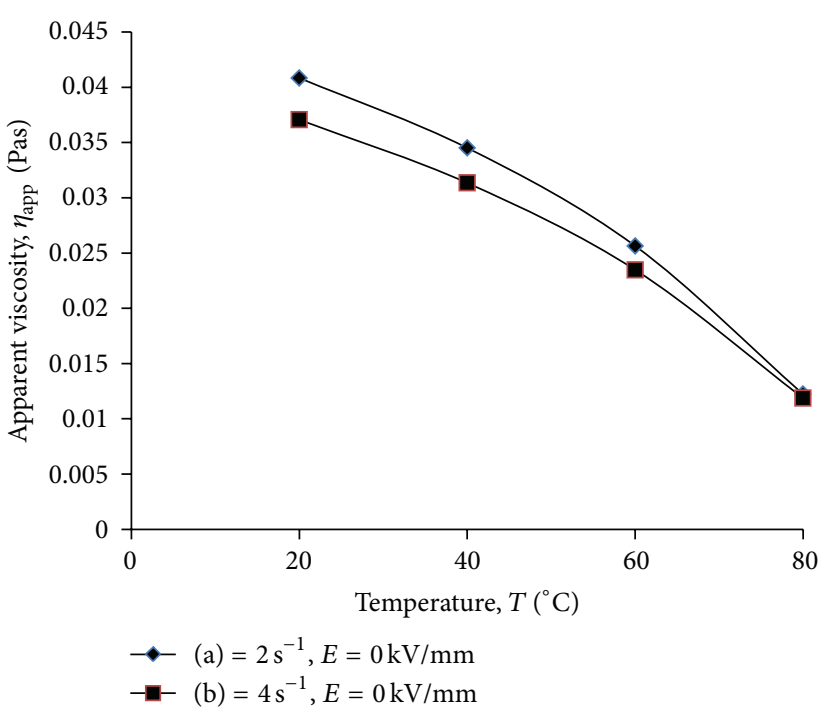

Figure 2: Viscosity (Pas) versus temperature, $\left({ }^{\circ} \mathrm{C}\right)$ for $(\mathrm{a})=2 \mathrm{~s}^{-1}$, $E=0 \mathrm{kV} / \mathrm{mm}$, and $(\mathrm{b})=4 \mathrm{~s}^{-1}, E=0 \mathrm{kV} / \mathrm{mm}$.

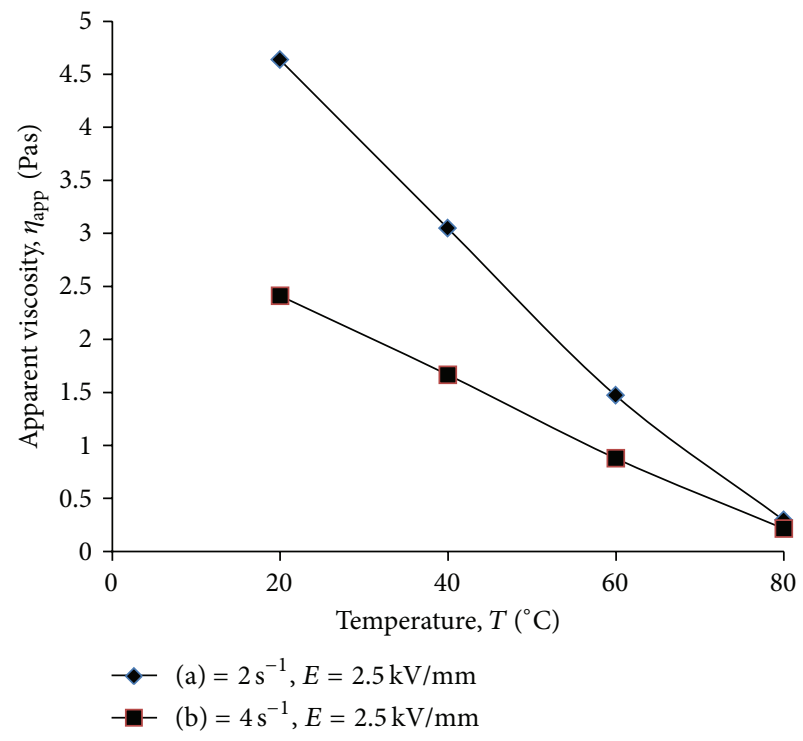

Figure 3: Viscosity (Pas) versus temperature, $\left({ }^{\circ} \mathrm{C}\right)$ for $(\mathrm{a})=2 \mathrm{~s}^{-1}$, $E=2.5 \mathrm{kV} / \mathrm{mm}$, and $(\mathrm{b})=4 \mathrm{~s}^{-1}, E=2.5 \mathrm{kV} / \mathrm{mm}$.

6.1. Effect of Temperature on the Viscosity, Stiffness, and Damping Characteristics. This section presents the effect of temperature on the viscosity and dynamic characteristics of the squeeze film damper for the specifications presented in Tables 1,2 (a), and 2(b).

The effect of temperature on the viscosity for different strain rates without the electric field is presented in Figure 2. The viscosity decreases with the temperature owing to loosening of the fibrillar structures with temperature.

Figure 3 indicates the variation of viscosity with temperature with the applied electric field at $2.5 \mathrm{kV} / \mathrm{mm}$. The viscosity is also found to decrease with the strain rate as indicated by Figures 2 and 3 since the ER Fluid is a shear thinning fluid. 

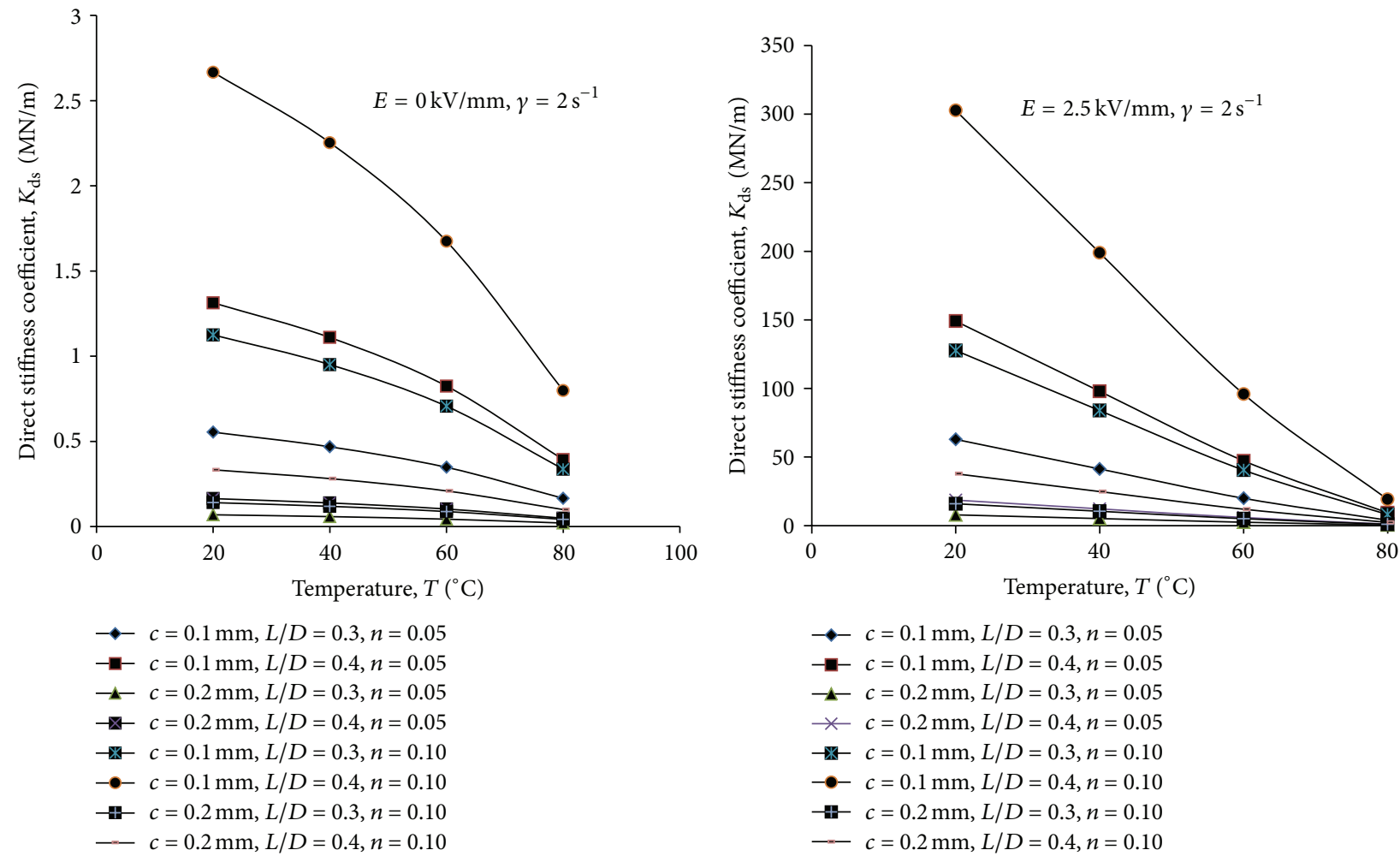

(a)

(b)

Figure 4: Direct stiffness coefficient, $K_{\mathrm{ds}}$, $(\mathrm{MN} / \mathrm{m})$ versus temperature, $\left({ }^{\circ} \mathrm{C}\right)$ for (a) $E=0 \mathrm{kV} / \mathrm{mm}$, and (b) $E=2.5 \mathrm{kV} / \mathrm{mm}$ under a constant strain rate, $\dot{\gamma}=2 \mathrm{~s}^{-1}$.
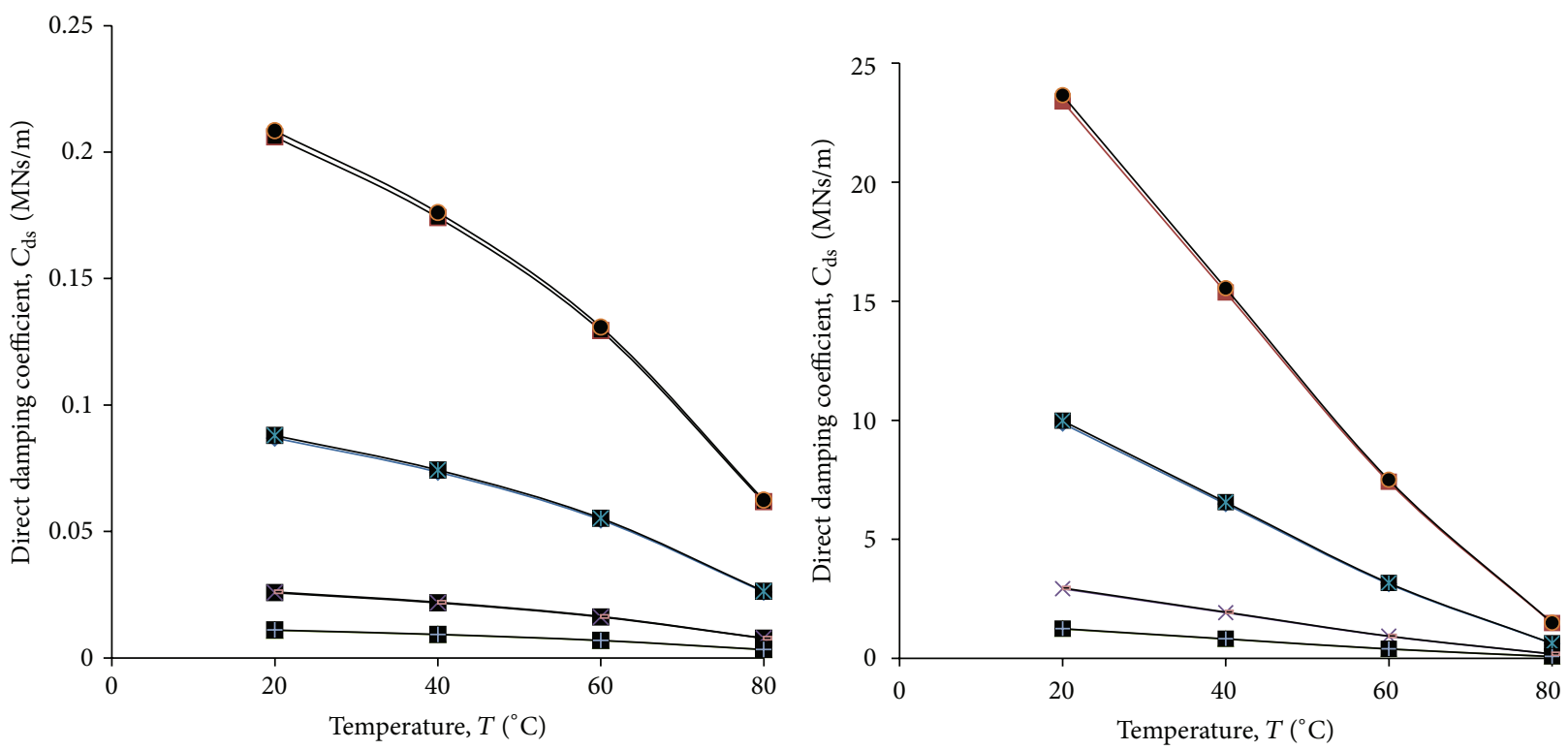

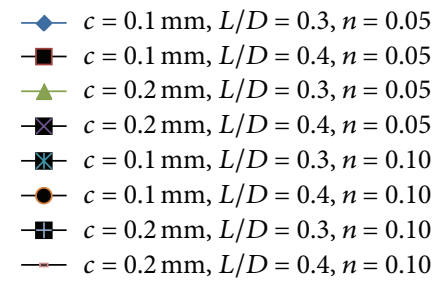

(a)

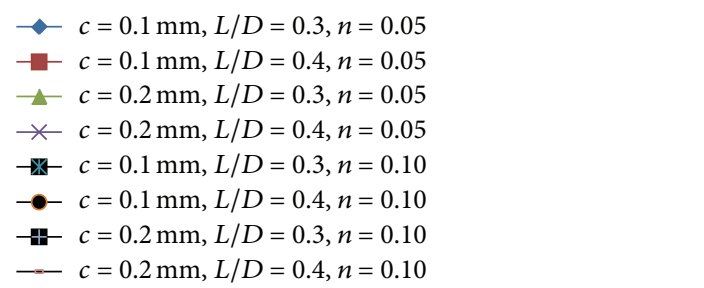

(b)

FIGURE 5: Direct damping coefficient, $C_{\mathrm{ds}},(\mathrm{MNs} / \mathrm{m})$ versus temperature, $\left({ }^{\circ} \mathrm{C}\right)$ for (a) $E=0 \mathrm{kV} / \mathrm{mm}$ and $(\mathrm{b}) E=2.5 \mathrm{kV} / \mathrm{mm}$ under a constant strain rate, $\dot{\gamma}=2 \mathrm{~s}^{-1}$. 

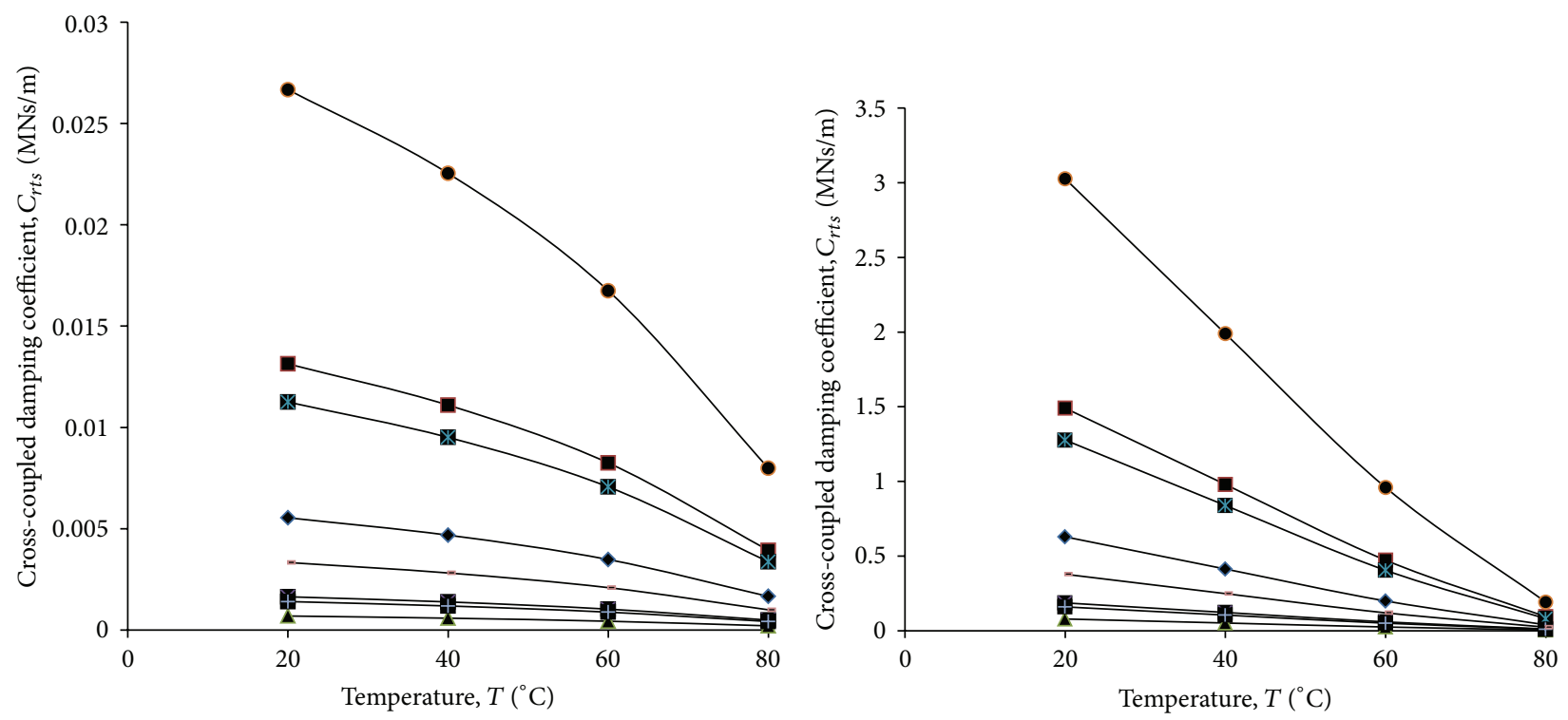

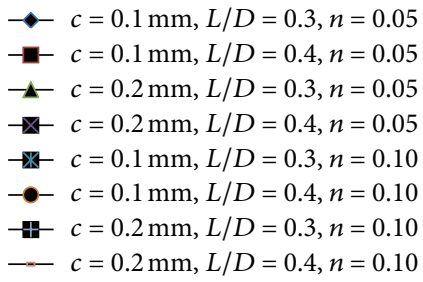

(a)

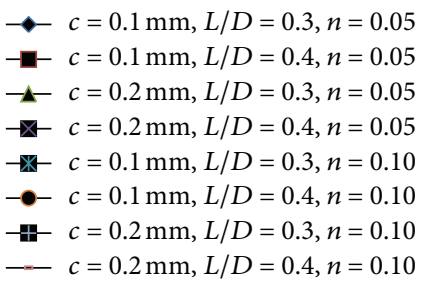

(b)

Figure 6: Cross-coupled damping coefficient, $C_{r t s}$, MNs $/ \mathrm{m}$ versus temperature, $\left({ }^{\circ} \mathrm{C}\right.$ ) for (a) $E=0 \mathrm{kV} / \mathrm{mm}$ and (b) $E=2.5 \mathrm{kV} / \mathrm{mm}$ under a constant strain rate, $\dot{\gamma}=2 \mathrm{~s}^{-1}$.

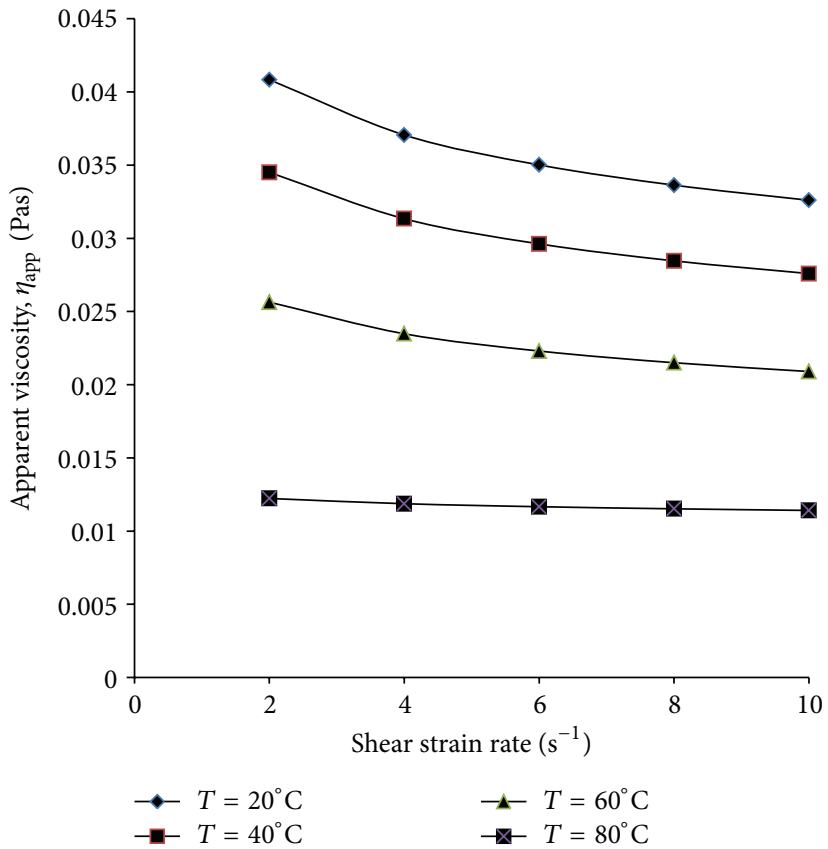

(a)

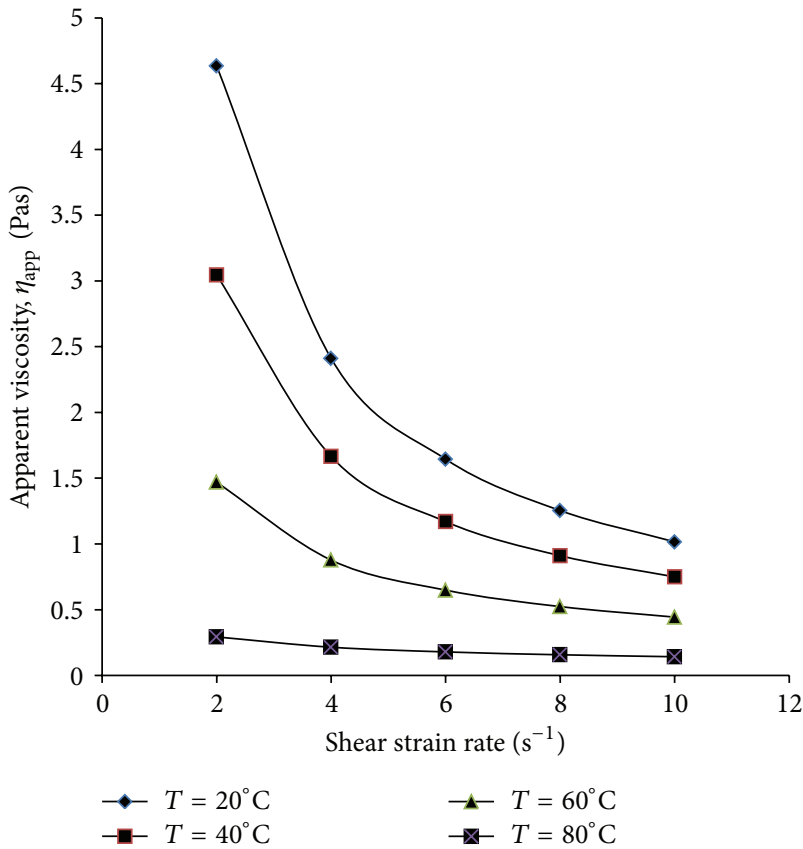

(b)

Figure 7: Apparent viscosity, $\eta_{\text {app }}$, Pas versus shear strain rate for (a) $E=0 \mathrm{kV} / \mathrm{mm}$ and (b) $E=2.5 \mathrm{kV} / \mathrm{mm}$ for different temperatures. 


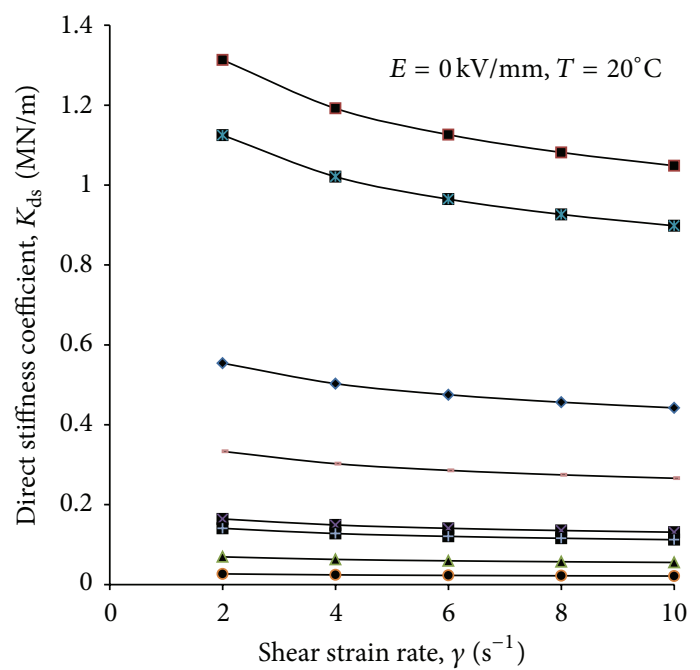

(a)

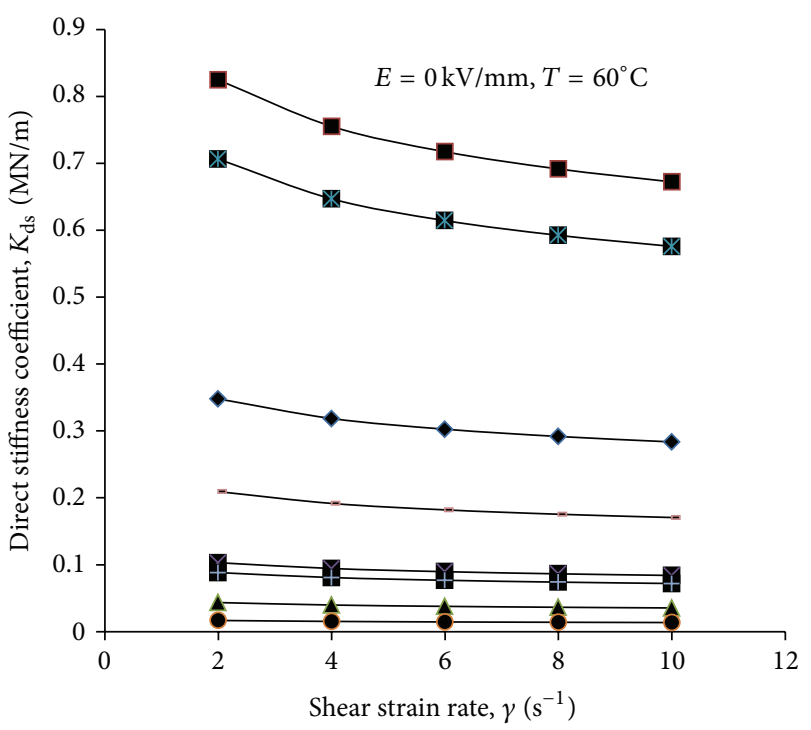

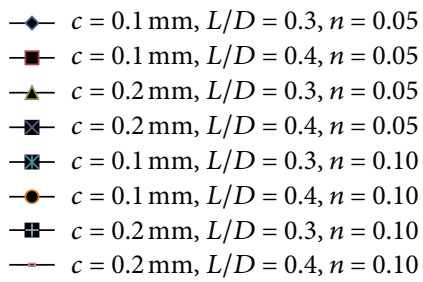

(c)

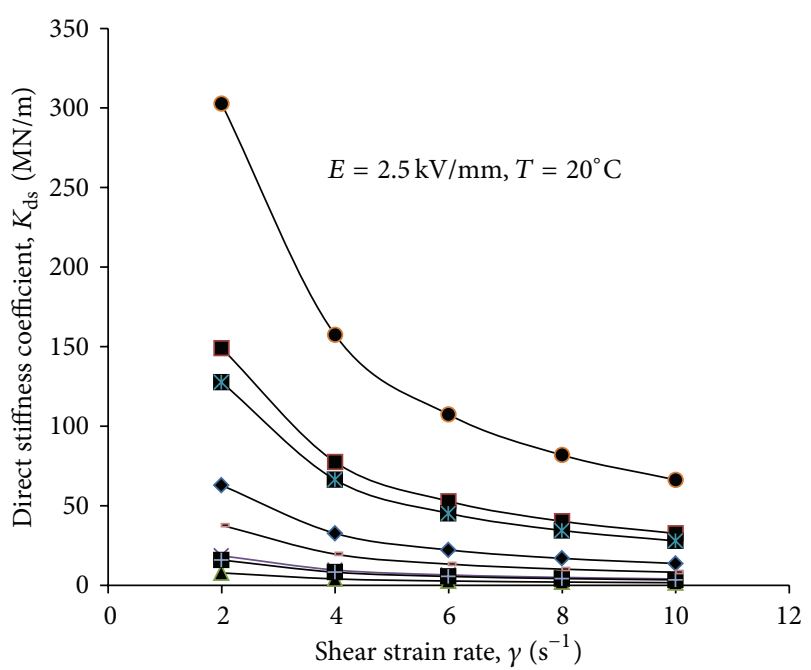

(b)

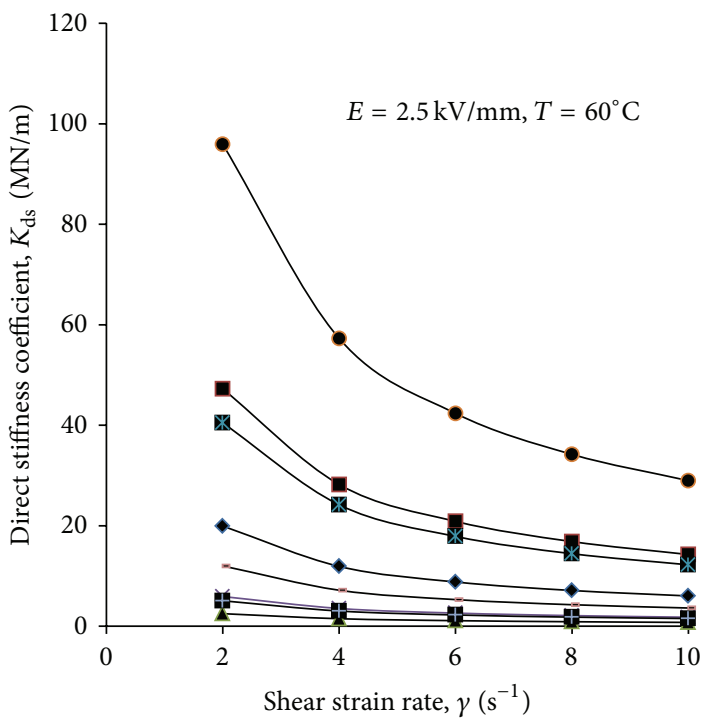

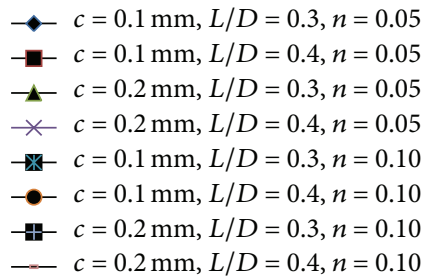

(d)

Figure 8: Direct stiffness coefficient, $\mathrm{MN} / \mathrm{m}$ versus shear strain rate, $\mathrm{s}^{-1}$, for (a) $E=0 \mathrm{kV} / \mathrm{mm}, T=20^{\circ} \mathrm{C}$; (b) $E=2.5 \mathrm{kV} / \mathrm{mm}, T=20^{\circ} \mathrm{C}$; (c) $E=0 \mathrm{kV} / \mathrm{mm}, T=60^{\circ} \mathrm{C}$; and (d) $E=2.5 \mathrm{kV} / \mathrm{mm}, T=60^{\circ} \mathrm{C}$.

However, it should be noticed that the viscosity increases by many orders under the action of the field.

The constants $\eta_{0}$ and $B$ of the temperature- viscosity model of the ER fluid (using either the Reynolds equation or the Arrhenius equation as outlined in (4) and (5), resp.) are presented in Table 3.

The effect of temperature on the direct stiffness, direct damping, and cross-coupled damping coefficients are presented through Figures 4(a), 4(b), 5(a), 5(b), 6(a), and 6(b) for electric field intensities of $0 \mathrm{kV} / \mathrm{mm}$ and $2.5 \mathrm{kV} / \mathrm{mm}$. The dynamic coefficients decrease with temperature in accordance with (4) and (5), respectively.

6.2. Effect of Electric Field Intensity and Shear Strain Rate on the Viscosity, Stiffness, and Damping Characteristics of ER Squeeze Film Dampers. The apparent viscosity of the ER fluid is depicted in Figures 7 (a) and $7(\mathrm{~b})$ as a function of the shear strain rate for different electric field intensities, 


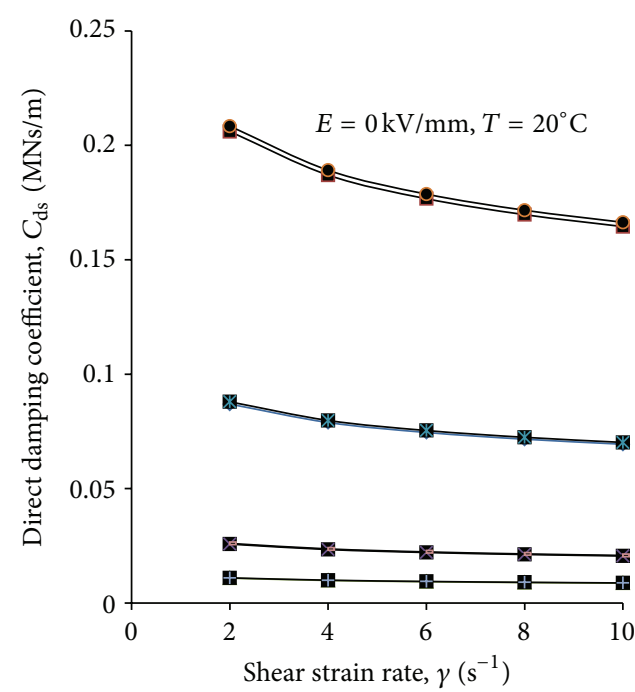

(a)

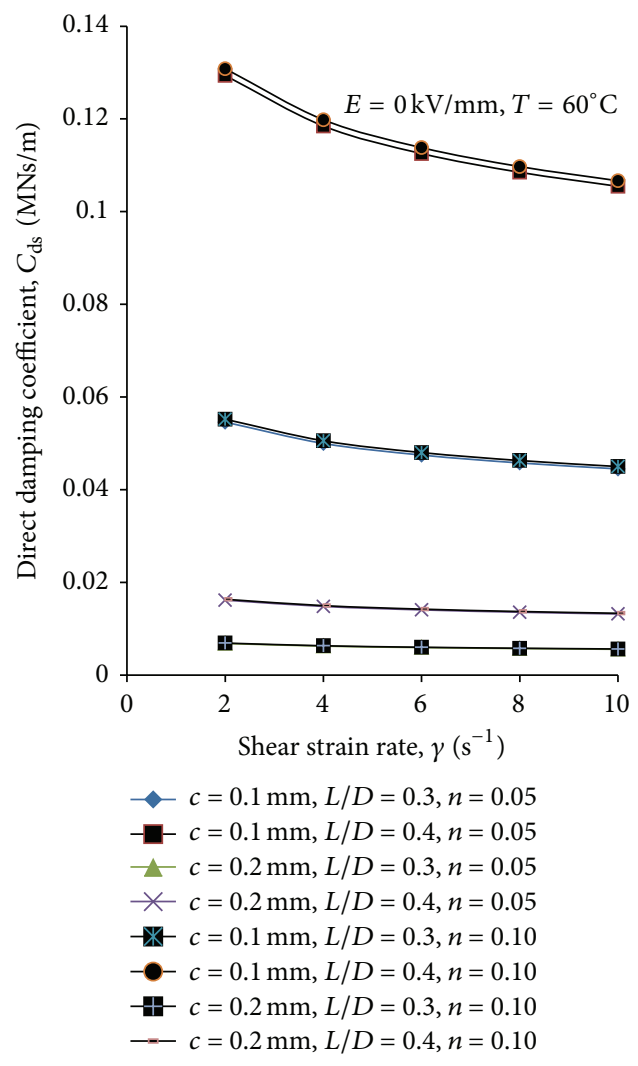

(c)

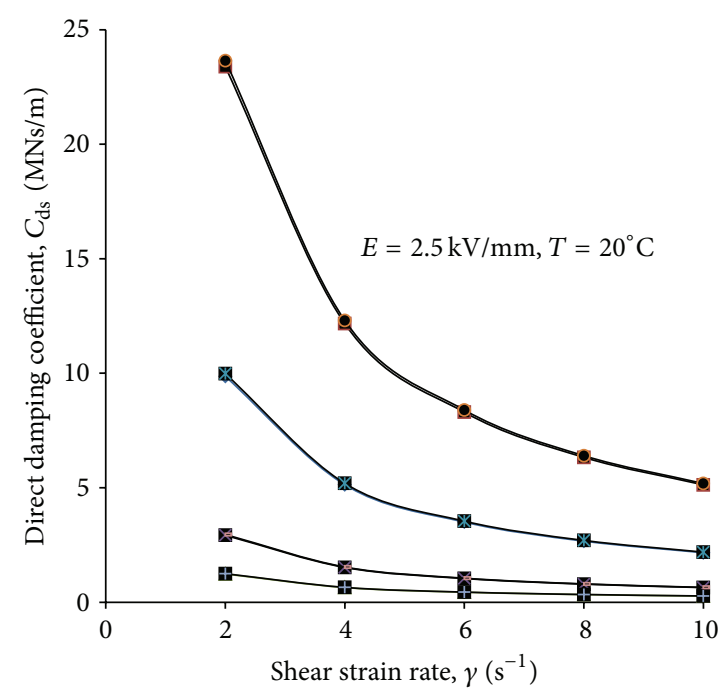

(b)

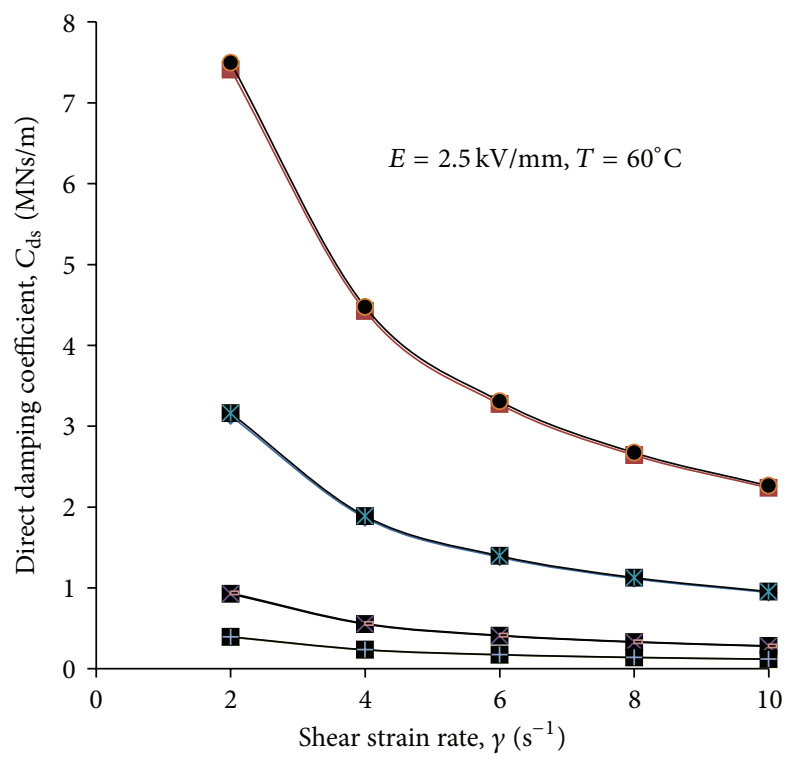

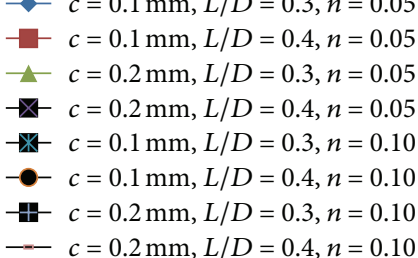

(d)

FIGURE 9: Direct damping coefficient, MNs $/ \mathrm{m}$ versus shear strain rate, $\mathrm{s}^{-1}$, for (a) $E=0 \mathrm{kV} / \mathrm{mm}, T=20^{\circ} \mathrm{C}$; (b) $E=2.5 \mathrm{kV} / \mathrm{mm}, T=20^{\circ} \mathrm{C}$; (c) $E=0 \mathrm{kV} / \mathrm{mm}, T=60^{\circ} \mathrm{C}$; and (d) $E=2.5 \mathrm{kV} / \mathrm{mm}, T=60^{\circ} \mathrm{C}$.

$E=0 \mathrm{kV} / \mathrm{mm}$ and $2.5 \mathrm{kV} / \mathrm{mm}$, respectively. The viscosity increases by many orders on the application of the field and decreases with increase in the shear strain rate as envisaged in these diagrams.

The effect of electric field on the dynamic characteristics of the ER damper are presented for temperatures $20^{\circ} \mathrm{C}$ and $60^{\circ} \mathrm{C}$ with and without the electric field through
Figures 8,9 , and 10 as a function of the shear strain rate. All the dynamic characteristics show identical behavior and increase with the electric field through Figures 8, 9, and 10, respectively as is apparent from these plots. However, these characteristics decrease with temperature as can be seen through Figures 8, 9, and 10, respectively, for $20^{\circ} \mathrm{C}$ and $60^{\circ} \mathrm{C}$ temperatures. However, the dynamic characteristics decrease 


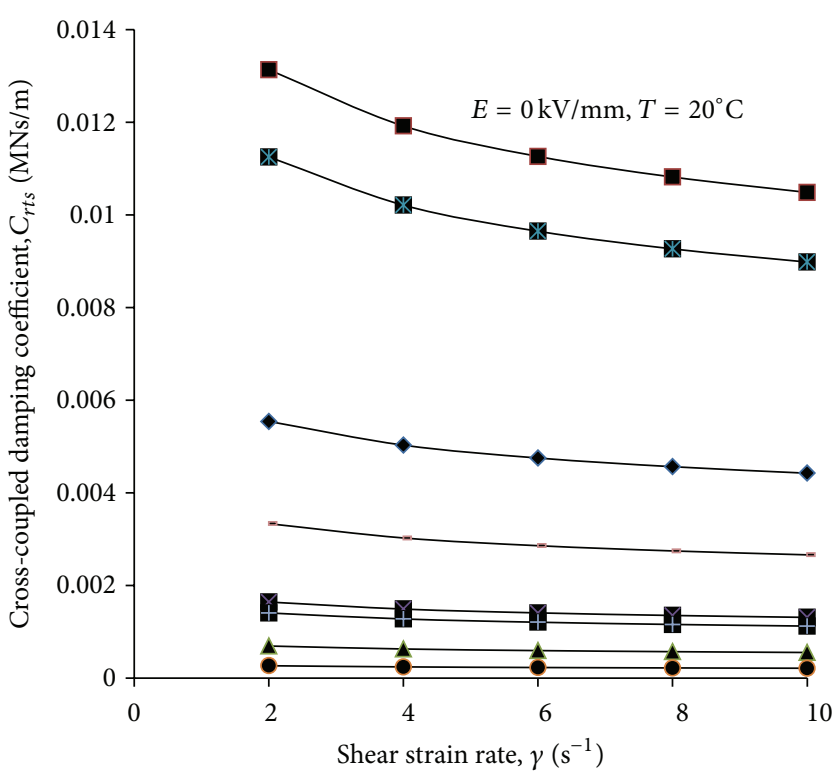

(a)

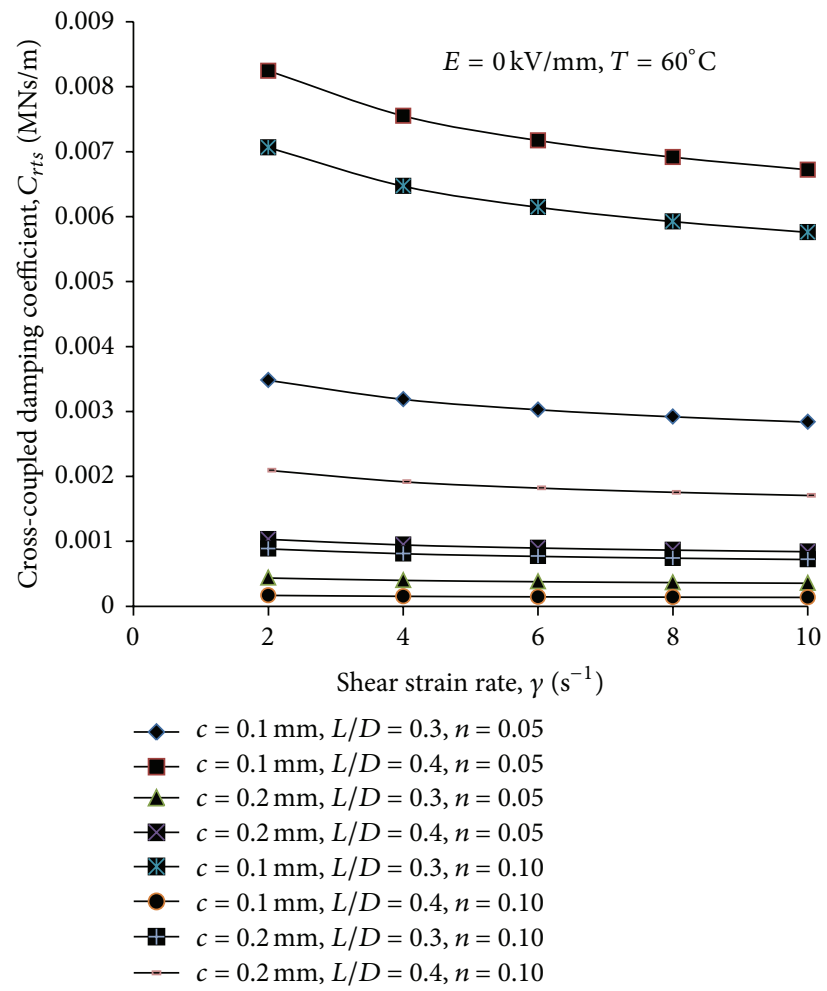

(c)

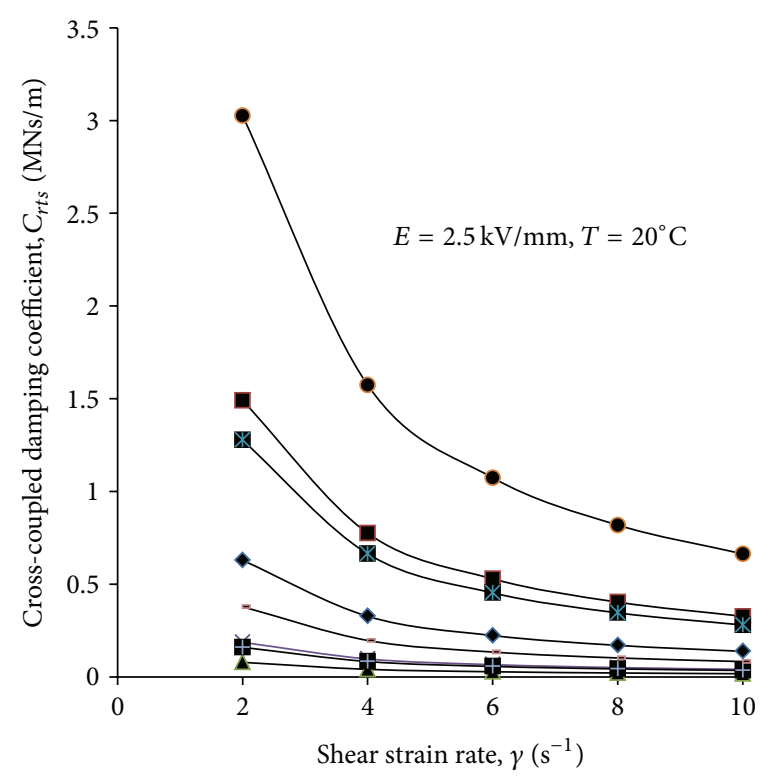

(b)

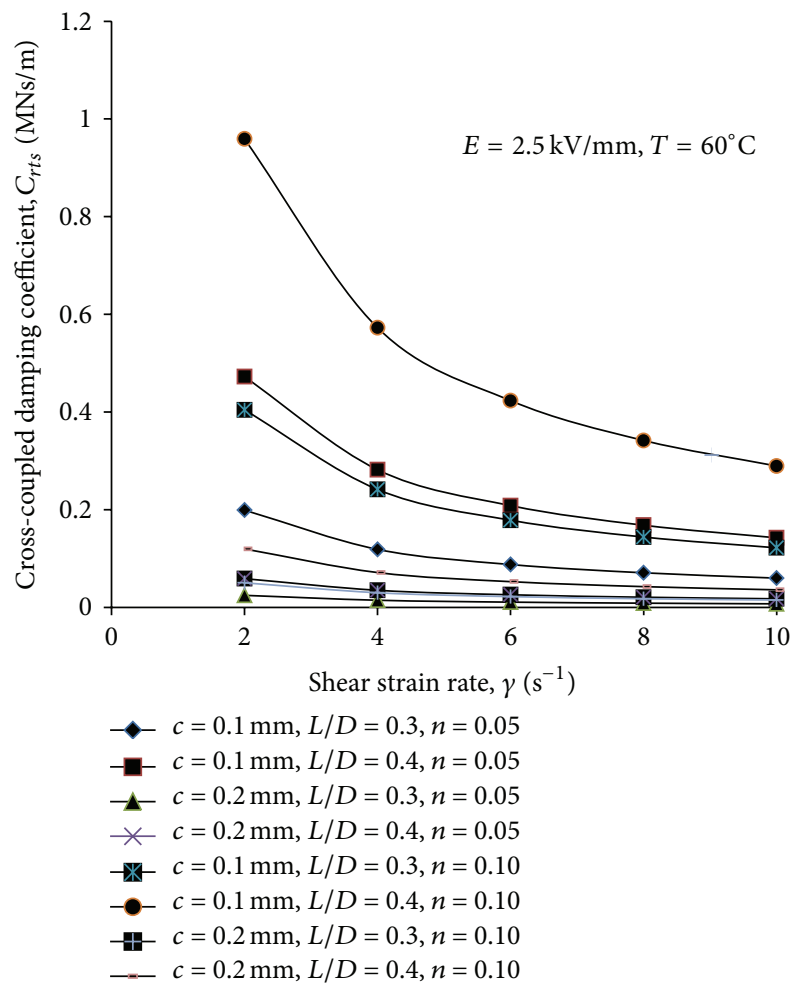

(d)

Figure 10: Cross-coupled damping coefficient, MNs $/ \mathrm{m}$ versus shear strain rate, $\mathrm{s}^{-1}$, for (a) $E=0 \mathrm{kV} / \mathrm{mm}, T=20^{\circ} \mathrm{C} ;(\mathrm{b}) E=2.5 \mathrm{kV} / \mathrm{mm}, T=$ $20^{\circ} \mathrm{C}$; (c) $E=0 \mathrm{kV} / \mathrm{mm}, T=60^{\circ} \mathrm{C}$; and (d) $E=2.5 \mathrm{kV} / \mathrm{mm}, T=60^{\circ} \mathrm{C}$.

with increase in the strain rate in accordance with the viscosity behavior (shear thinning fluid).

\section{Conclusions}

The effect of temperature on the dynamic (stiffness and damping) characteristics of an ER Fluid short squeeze film damper is presented in this paper. The dynamic coefficients increase with the electric field due to increase in viscosity with the electric field since it produces fibrillar chains or layers which retard the flow of the fluid and consequently increases the viscosity. However, the opposite effect happens at high temperatures and the fibrillar structures are broken at this temperature resulting in decreased viscosity. These coefficients, thus, decrease with increase in temperature of the ER 
fluid. They also decrease with the shear strain rate as the viscosity decreases with shear strain rate. For a particular damper configuration, these coefficients increase with decrease in clearance, increase in $L / D$ ratio and eccentricity ratio.

\section{Nomenclature}

\begin{tabular}{|c|c|}
\hline$\tau:$ & Total shear stress, N/m² $(\mathrm{Pa})$ \\
\hline$\tau_{\mathrm{yd}}:$ & Dynamic yield stress, $\mathrm{N} / \mathrm{m}^{2}(\mathrm{~Pa})$ \\
\hline$\eta:$ & Field independent plastic viscosity, Ns $/ \mathrm{m}^{2}$ \\
\hline$\omega:$ & Excitation frequency, rad/s \\
\hline$\rho:$ & Density, $\mathrm{kg} / \mathrm{m}^{\frac{3}{3}}$ \\
\hline$\alpha:$ & Attitude angle, degree \\
\hline$\theta:$ & Angular coordinate of the damper, degree \\
\hline$\dot{\gamma}:$ & Shear strain rate, $\mathrm{s}^{-1}$ \\
\hline$\eta_{\text {app }}:$ & Apparent viscosity due to the field, Pas \\
\hline$c:$ & Clearance in the damper, $\mathrm{m}$ \\
\hline$C_{r r s}:$ & $\begin{array}{l}\text { Short bearing radial damping coefficient, } \\
\mathrm{MNs} / \mathrm{m}\end{array}$ \\
\hline$C_{r t s}:$ & $\begin{array}{l}\text { Short bearing cross-coupled damping } \\
\text { coefficient, MNs/m }\end{array}$ \\
\hline$C_{t t s}=C_{\mathrm{ds}}:$ & $\begin{array}{l}\text { Short bearing tangential or direct damping } \\
\text { coefficient, } \mathrm{MNs} / \mathrm{m}\end{array}$ \\
\hline$D:$ & Damper diameter, $\mathrm{m}$ \\
\hline$e:$ & Eccentricity or whirl radius, $\mathrm{m}$ \\
\hline$E:$ & Electric field intensity, $\mathrm{kV} / \mathrm{mm}$ \\
\hline$F_{r}:$ & Radial force in the damper, $\mathrm{N}$ \\
\hline$F_{t}:$ & Tangential force, $\mathrm{N}$ \\
\hline$K:$ & Consistency index and $K>0$ \\
\hline$K_{\mathrm{ds}}=K_{r r s}:$ & $\begin{array}{l}\text { Short bearing direct stiffness coefficient, } \\
\text { GN/m }\end{array}$ \\
\hline$L:$ & Length of the damper, $\mathrm{m}$ \\
\hline$m:$ & Fluid parameters and $m>0$ \\
\hline$n:$ & Eccentricity ratio $=e / c$ \\
\hline$n_{1}:$ & Viscosity exponent or behavior index \\
\hline$r:$ & Damper radius, $\mathrm{m}$ \\
\hline $\operatorname{sgn}(\dot{\gamma}):$ & Signum function \\
\hline$t:$ & Time, s \\
\hline$U:$ & Surface velocity, m/s \\
\hline$V_{r}:$ & Radial whirl velocity, $\mathrm{m} / \mathrm{s}$ \\
\hline$V_{t}:$ & Tangential whirl velocity, $\mathrm{m} / \mathrm{s}$ \\
\hline
\end{tabular}

\section{Conflict of Interests}

The authors declare that there is no conflict of interests regarding the publication of this paper.

\section{References}

[1] O. Bonneau and J. Frêne, "Non-linear behaviour of a flexible shaft partly supported by a squeeze film damper," Wear, vol. 206, no. 1-2, pp. 244-250, 2007.

[2] S. Morishita and T. Ura, "ER fluid applications to vibration control devices and an adaptive neural-net controller," Journal of Intelligent Material Systems and Structures, vol. 4, no. 3, pp. 366$372,1993$.
[3] K. D. Weiss, T. G. Duclos, J. D. Carlson, M. J. Chrzan, and A. J. Margida, "High Strength Magneto- and Electro-rheological Fluids," SAE Technical Paper 932451, 1993.

[4] W. Kordonsky, "Elements and devices based on magnetorheological effect," Journal of Intelligent Material Systems and Structures, vol. 4, no. 1, pp. 65-69, 1993.

[5] K. D. Weiss and J. D. Carlson, "A growing attraction to magnetic fluids," Machine Design, vol. 66, no. 15, pp. 61-64, 1994.

[6] C. Carmignani and P. Forte, "Active squeeze film dampers in rotor dynamics, AIMETA," International Journal of Applied Mechanics and Engineering, vol. 6, no. 4, pp. 1-8, 2001.

[7] P. Forte, M. Paterno, and E. A. Rustishi, "Magneto Rheological fluid damper for Rotor applications," International Journal of Rotating Machinery, vol. 10, no. 3, pp. 175-182, 2004.

[8] B. Mohammad Ayani and L. Hosseini, "The Effect of Temperature and Electric Field on the Behavior of Electrorheological Fluids," in Proceedings of the 14th Annual International Mechanical Engineering Conference, 2006.

[9] C. Guang and Y. Song Huat, "Research on MR fluids," Applied Research Project Report RG63/96, School of Mechanical and Production Engineering, Nanyang Technological University, Singapore, 1996.

[10] J. S. Rao, Rotordynamics, New Age International, New Delhi, India, 3rd edition, 2006. 

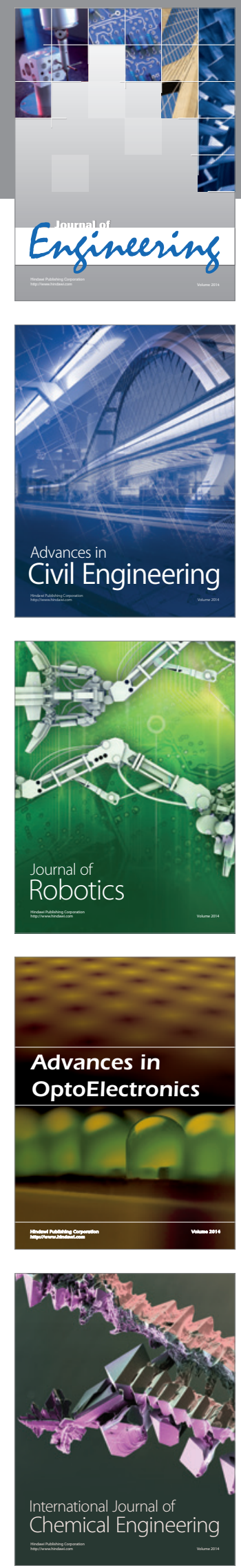

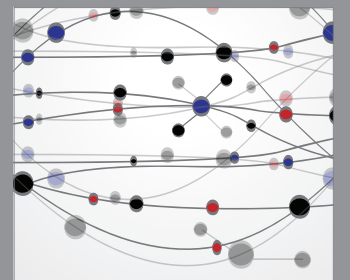

The Scientific World Journal
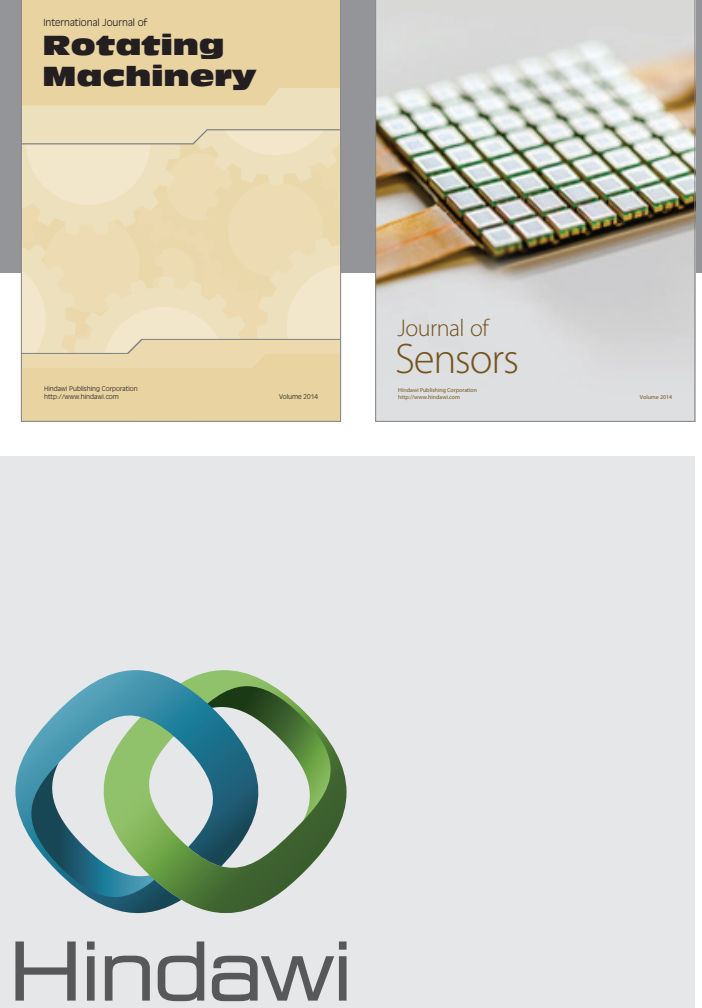

Submit your manuscripts at http://www.hindawi.com
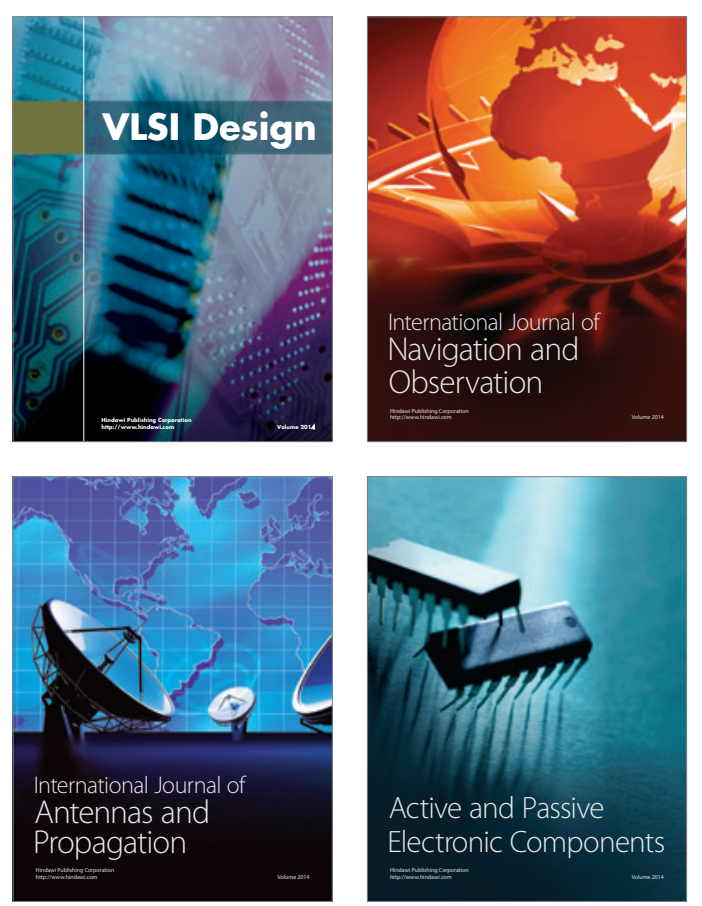
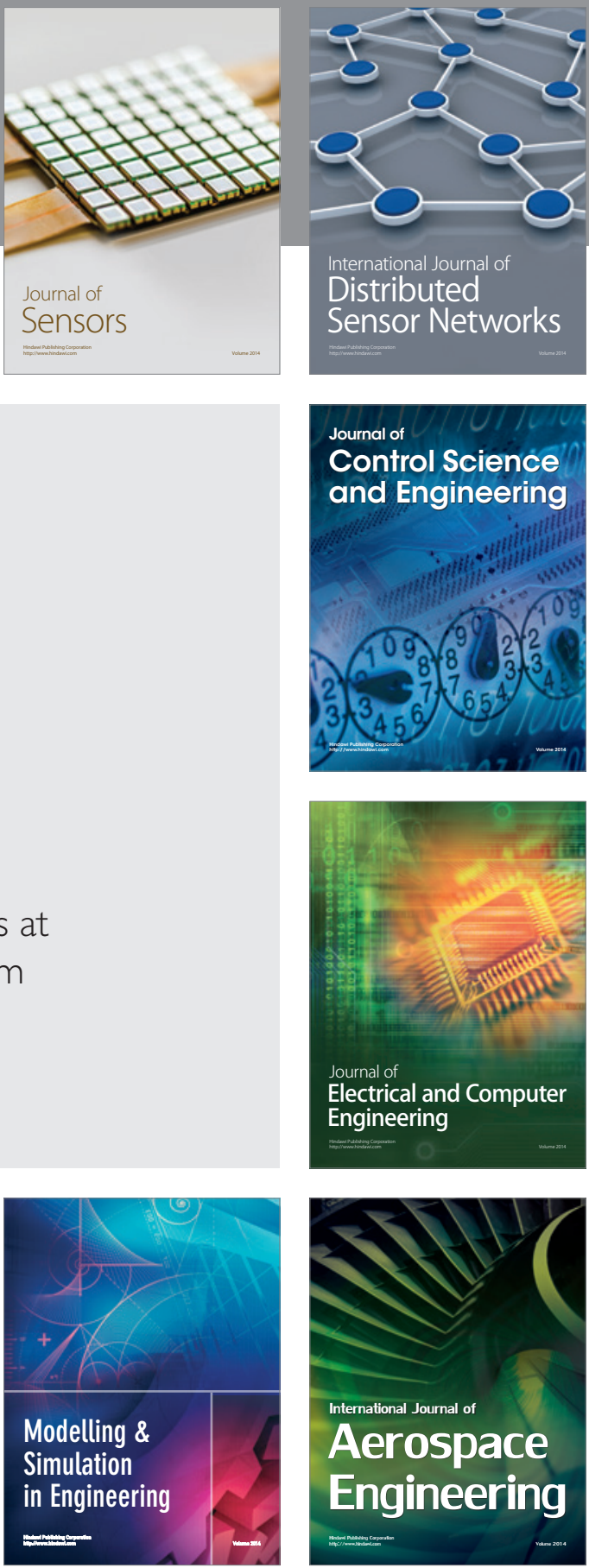

Journal of

Control Science

and Engineering
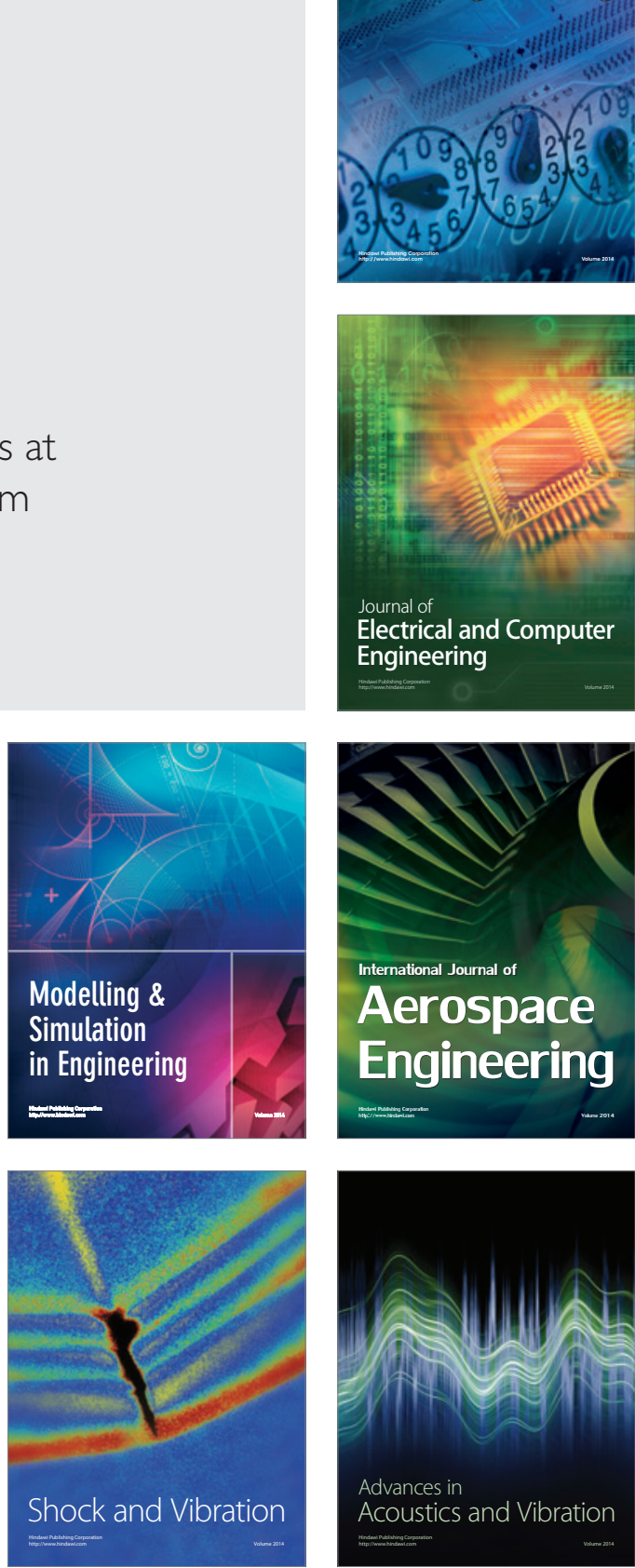